\title{
PROFESSOR INICIANTE: DIFICULDADES NO EXERCÍCIO DA PRÁTICA PEDAGÓGICA NA EDUCAÇÃO INFANTIL
}

\author{
Mayara Ap. Pereira Menezes, Tatyane Bonora Silva da Costa, Augusta Boa Sorte Oliveira Klébis. \\ Universidade do Oeste Paulista - UNOESTE. Faculdade de Ciências, Letras e Educação - FACLEPP, Presidente Prudente, \\ SP.
}

\section{RESUMO}

Este artigo apresenta resultados de uma pesquisa de iniciação científica intitulada "Professor Iniciante: dificuldades no exercício da prática pedagógica na educação infantil”, realizada em algumas salas de Pré-escolas dos municípios de Presidente Prudente e região, com o objetivo de buscar compreender quais as dificuldades que os professores iniciantes oriundos do curso de Pedagogia encontram ao iniciar a sua carreira docente na Educação Infantil. Fundamentada em autores como Tardif e Raymond (2000), Tardif (2014) Huberman (2000) e Marcelo (2009) dentre outros, adotou a abordagem de natureza qualitativa e a metodologia estudo exploratório. A pesquisa de campo teve como instrumento de coleta de dados a aplicação de questionários para identificar o perfil e as dificuldades de professores iniciantes, que atuam na Pré-escola. Diante das análises dos questionários foi possível observar que dentre as dificuldades encontradas pelos participantes da pesquisa estão: a insegurança e o medo de errar; o relacionamento entre família e escola bem como a questão da valorização profissional. Para que tais dificuldades sejam superadas, se faz necessário uma maior articulação entre a formação inicial e a formação continuada, assim como um maior envolvimento dos gestores e compromisso das políticas públicas.

Palavras-Chave: Professores iniciantes, Educação Infantil, Prática Pedagógica, Necessidades formativas.

\section{BEGINNER TEACHER: DIFFICULTIES IN PRACTICE THE EXERCISE OF TEACHING IN EARLY CHILDHOOD EDUCATION}

\begin{abstract}
This article presents results of a scientific initiation research entitled "Professor Novice: difficulties in the exercise of teaching practice in early childhood education" held in some rooms Preschools of Presidente Prudente municipalities and region, in order to seek to understand what difficulties that novice teachers from the faculty of Education are to begin his teaching career in Early Childhood Education. Based on authors such as Tardif and Raymond (2000), Tardif (2014) Huberman (2000) and Marcelo (2009) among others, adopted the qualitative approach and exploratory study methodology. The field research was data collection instrument the application of questionnaires to identify the profile and the difficulties of beginning teachers, who work in pre-school. On the analysis of the questionnaires it was observed that among the difficulties encountered by survey participants are: insecurity and fear of making mistakes; the relationship between family and school as well as the issue of professional development. For such difficulties can be overcome if greater links between initial training and continuing education, as well as greater involvement of managers and commitment of public policies is needed.
\end{abstract}

Keywords: beginners Teachers, Early Childhood Education, Teaching Practice, training needs. 


\section{INTRODUÇÃO}

Atualmente é comum observar a queixa de professores iniciantes no exercício de sua prática, diante das dificuldades em relacioná-las com as teorias que aprendem no decorrer da sua formação acadêmica. Mesmo quando ao término do curso se sentem preparados para assumir a sala de aula e idealizam como será a construção da sua carreira, ao se depararem com a realidade escolar percebem que na prática as coisas podem ser um pouco diferente daquilo que sonharam e acabam frustrados e desmotivados. Para Nono e Mizukami (2006, p 384) o início da docência "é um período marcado, em geral, pela desilusão e pelo desencanto e que corresponde à transição da vida de estudante para a vida mais exigente do trabalho".

Araújo (2005,p. 64) complementa, com relação à formação inicial, ser necessário discutir o papel das universidades. "Significa pensarmos sobre de que forma os conhecimentos produzidos em nossas universidades, faculdades e núcleos de estudos e pesquisas vêm sendo utilizados para a promoção desses profissionais". De acordo com a autora, o início da prática docente tem um peso muito grande no processo de desenvolvimento desse profissional e, portanto, deverá ter como apoio a continuidade da formação do professor. Assim propõe uma sólida articulação entre a formação inicial e a formação continuada. Implica, portanto, no compromisso das instituições formadoras em manter um diálogo permanente com a escola básica, de forma a trazer para o seu interior a realidade e os problemas vivenciados nas escolas, em especial, de educação infantil e ensino fundamental.

Da mesma forma, Tardif (2014, p. 261) salienta que "os primeiros anos de prática são decisivos na aquisição do sentimento de competência e no estabelecimento das rotinas de trabalho, ou seja, na estimulação da prática profissional".

Nesse sentido, Perrenoud (2002, p.17) afirma que "a formação de bons principiantes tem a ver com a formação de pessoas capazes de evoluir, de aprender de acordo com a experiência, refletindo sobre o que gostariam de fazer, sobre o que realmente fizeram e sobre os resultados de tudo isso".

Portanto, não se pode desconsiderar o papel da universidade na formação continuada do profissional docente, uma vez que os conhecimentos sofrem transformações constantes, o que torna a articulação entre a escola básica e as instituições formadoras indispensável a todos, haja vista a exigência de acompanhar a inovação e o desenvolvimento relacionado ao conhecimento, à ciência e à tecnologia, bem como a necessidade de refletir e aperfeiçoar criticamente a prática pedagógica para uma educação transformadora (ALMEIDA; SOARES, 2012).

Para Gabardo e Hobold (2011, p. 95) é fundamental que no início da docência sejam garantidos espaços que promovam uma aproximação e interlocução com professores mais experientes e com a equipe de gestores, bem como um acompanhamento mais efetivo do trabalho que desenvolvem

Sobretudo, a escola terá que se constituir em um espaço coletivo de formação, capaz de promover a socialização de experiências e a reflexão teórico-prática do fazer pedagógico. Corroborando com essa ideia, Silveira e Rausch (2014) salientam que no início da docência é fundamental uma formação continuada significativa e participativa, que leve em consideração os acontecimentos cotidianos e as dificuldades com as quais o professor se depara na medida em que vai exercendo sua prática.

Dessa forma, essa pesquisa teve como objetivo geral trazer para o debate os desafios enfrentados pelos professores iniciantes de Educação Infantil no desempenho de sua função. Mais especificamente se propôs: a) discutir a formação docente (inicial e continuada) na visão de autores diversos e na legislação em vigor; b) analisar as dificuldades que os professores iniciantes do curso de Pedagogia que atuam em escolas públicas de Presidente Prudente e região se deparam no desempenho de sua função na educação infantil, bem como sobre suas necessidades 
formativas; c) apresentar marcadores de reflexão que apontam para uma maior articulação entre formação inicial e a escola básica, mais especificamente, de Educação Infantil .

\section{METODOLOGIA}

Trata-se de uma pesquisa de abordagem qualitativa, cuja opção metodológica foi pelo estudo exploratório, uma vez que buscou compreender um fenômeno educativo, dentro de uma dada realidade, com toda a sua complexidade, ou seja, as dificuldades e necessidades formativas de professores iniciantes na Educação Infantil. Assim, optou-se por uma pesquisa de campo que utilizou como instrumento de coleta de dados a aplicação de questionários, compostos por questões abertas e fechadas, com a finalidade de identificar o perfil e as principais dificuldades de professores iniciantes, que atuam na Educação Infantil da rede municipal de Presidente Prudente e região, abrangendo o Município de Martinópolis e seu Distrito, Teçaindá, além do Município de Rancharia. Os questionários foram respondidos por cinco professores iniciantes na Educação Infantil que atuam há no máximo cinco anos. Tais questionários foram aplicados durante os meses de abril e maio de 2016. Ressalta-se o fato de que os participantes da pesquisa exercem sua função em escolas públicas.

Para o desenvolvimento da pesquisa, fez-se necessário a aprovação da Coordenadoria de Pesquisa, Desenvolvimento e Inovação (CPDI) da Pró-Reitoria de Pesquisa e Pós-Graduação e pelo Comitê de Ética e Pesquisa (CEP) sob no. 3136, bem como junto a Plataforma Brasil, no. CAAE: 55472416.3.0000.551. Após a aprovação da pesquisa, aos sujeitos que se dispuseram a dela participar foi encaminhado o TCLE - Termo de Consentimento Livre e Esclarecido que Ihes garantiu o sigilo e direito de desistência da pesquisa, caso assim o desejassem.

Os dados obtidos por meio dos questionários foram tabulados e submetidos a uma análise qualitativa, nos aspectos: I) Dados pessoais, que buscou traçar o perfil socioeconômico dos professores. II) Dados sobre a formação, que contemplou questões fechadas e discursivas que objetivaram investigar a formação acadêmica dos docentes. III) Necessidades formativas e dificuldades dos professores na educação infantil.

\section{SER PROFESSOR NA EDUCAÇÃO INFANTIL: OS DESAFIOS DA FORMAÇÃO INICIAL E CONTINUADA}

Historicamente, a docência na Educação Infantil esteve muito atrelada à visão de cuidado e, portanto, era vista como um prolongamento das atividades domésticas. Dessa forma, se fez necessária uma política de formação docente que valorizasse os conhecimentos fundamentais ao exercício da docência na educação infantil. Implica em considerar a formação docente como um continuun capaz de manter permanente articulação entre formação inicial e continuada, estabelecendo uma relação dialética entre teoria prática docente, de forma a permitir que o professor tenha uma visão crítica reflexiva dos problemas com presentes no cotidiano da sala de aula. Para tanto, Pimenta (2005, p. 26) afirma que:

[...] Os saberes teóricos propositivos se articulam, pois, aos saberes da prática, ao mesmo tempo ressignificando-os e sendo por eles ressignificados. O papel da teoria é oferecer aos professores perspectivas de análises para compreender os contextos históricos, sociais, culturais, organizacionais, e de si mesmos como profissionais, nos quais se dá sua atividade docente, para neles intervir, transformando-os.

Nessa perspectiva, a contribuição de Imbernón (2011) é muito significativa ao ressaltar a importância da formação inicial garantir ao futuro docente o desenvolvimento de saberes, contextualizados, nas suas mais diversas dimensões: científica, cognitiva, cultural, política, social, psicopedagógica e pessoal, para que assim possa "assumir a tarefa educativa em toda a sua complexidade, atuando reflexivamente com a flexibilidade e o rigor necessários" (p. 63). 
Portanto, a formação do professor que atua na Educação Infantil não pode prescindir de conhecimentos teóricos e práticos específicos do desenvolvimento infantil, em saberes e competências necessários a uma ação transformadora e consciente sobre o significado dessa etapa da infância na vida do ser humano. Para a Araújo (2005, p. 63) a "formação do profissional da Educação Infantil envolve uma realidade ainda mais complexa por se dedicar ao cuidado e à educação de crianças no início de seu desenvolvimento e que necessitam de uma atenção especial". Assim, há que se considerar que o currículo das instituições formadoras não pode estar alheio aos problemas vivenciados da educação básica. Corroborando com essa ideia Perrenoud (2002, p. 18) ressalta que

É importante, a partir da formação inicial, criar ambientes de análise da prática, ambientes de partilha das contribuições e de reflexão sobre a forma como se pensa, decide, comunica e reage em uma sala de aula. Também é preciso criar ambientes - que podem ser os mesmos- para o profissional trabalhar sobre si mesmo, trabalhar seus medos e suas emoções, onde seja incentivado o desenvolvimento da pessoa, de sua identidade.

Araújo (2005) expressa ainda a urgência em avançar na construção da identidade do professor de Educação Infantil, uma vez que até agora não se pode afirmar a existência de um projeto nacional consistente na formação desses profissionais. Urge, pois, trazer para o debate qual o perfil exigido para o profissional da educação infantil, de forma a atender as atuais demandas e, consequentemente, qual a formação necessária.

Nessa perspectiva, a análise dos dados da pesquisa de campo, apresentada a seguir, busca conhecer um pouco mais sobre como se dá o início da carreira de professores que atuam na Educação Infantil e quais as suas principais dificuldades e desafios.

\section{PERFIL DOS PROFESSORES INICIANTES}

Todos os participantes do questionário apresentam idades compreendidas na faixa etária entre 30 e 45 anos. Em relação ao sexo dos participantes, verificamos que $100 \%$ são mulheres, 0 que evidencia o processo de feminização da docência, dado que se manifestou desde os anos finais do império, com a expansão da ideia de que a educação da infância deveria ser atribuída à mulher, uma vez que a função docente passa a ser vista como um prolongamento do papel materno e da atividade da mulher no lar (TANURI, 2002).

Verificamos que a renda familiar da maioria das professoras (60\%) gira em torno de quatro a seis salários mínimos, e 40\% recebem entre um a três salários mínimos, sendo que nenhuma das participantes recebe mais do que 10 salários mínimos. Convém lembrar ainda que, os baixos salários acabam obrigando os professores a assumirem uma segunda ou terceira jornada docente, como complementação salarial. As implicações, nesse caso, quase sempre, são insatisfatórias, por comprometerem a qualidade do trabalho docente, uma vez que o cansaço e o estresse são quase certos em tais situações, conforme comprova Codo (1999) em um estudo com mais de 1500 professores do todo o Brasil.

\section{DADOS SOBRE A FORMAÇÃO PROFISSIONAL DOS PROFESSORES EM INÍCIO DE CARREIRA}

$\mathrm{Na}$ verificação dos dados observa-se que $100 \%$ dos professores frequentaram o ensino médio em escolas púbicas. Além disso, $20 \%$ cursaram o 2 Grau Regular, 20\% cursaram o 2ㅇ Grau Supletivo e 60\% frequentaram o Ensino Médio nos CEFAM - Centros de Formação e Aperfeiçoamento do Magistério. Observamos que 40\% das professoras cursaram Licenciatura em Pedagogia em Instituição Pública, e 60\% em Instituição Particular. 
Em uma das falas, uma professora cita o fato de ter sido a exigência do governo o principal motivo pela escolha do curso. A resposta desta professora reflete o que está estabelecido na meta 15 do Plano Nacional de Educação (PNE) - 2014-2024 que prevê que todos os professores da Educação Básica tenham formação específica de nível superior em curso de licenciatura na área de conhecimento em que atuam (BRASIL, 2014).

Verificou-se também que $100 \%$ das professoras iniciantes possuem uma pós-graduação, todas em nível de especialização. Além disso, é importante destacar que $20 \%$ possuem mestrado em andamento. Os dados revelam que as professoras estão em consonância com a proposta do PNE uma vez que este prevê em sua meta 16 “Formar, em nível de pós-graduação, 50\% (cinquenta por cento) dos professores da educação básica, até o último ano de vigência deste PNE (BRASIL, 2014). Cabe ressaltar que a crescente procura por cursos de pós-graduação pode ser explicada pela necessidade de uma constante atualização, demandada pelas atuais exigências na área educacional.

Para Marcelo (2009) é indispensável que os docentes busquem seu desenvolvimento profissional, o qual pode ser entendido como uma atitude permanente de indagação, de formulação de questões e procura de soluções. Tal atitude se relaciona ao fortalecimento da identidade profissional.

\section{NECESSIDADES FORMATIVAS E DIFICULDADES DOS PROFESSORES INICIANTES}

A iniciação em uma carreira é um período importante, pois sinaliza o início da socialização do docente e é nesse meio que o saber ser e o saber fazer serão incorporados pelos professores. Assim, o sentimento de pertencimento profissional vai sendo construído ao longo do tempo e é marcado pelo contexto de trabalho e de vida do professor (TARDIF \& RAYMOND, 2000). Para os autores, representa um período de tensões e inseguranças que necessita de um olhar acurado, no sentido de contribuir para que tais docentes caminhem em direção a uma prática consciente e transformadora.

Nessa perspectiva, foi possível observar que $40 \%$ das professoras ao iniciarem a docência não se sentiram preparadas, $60 \%$ disseram que estavam preparadas em temos e apenas $20 \%$ se sentem muito bem preparadas. Quanto ao motivo de não ter se sentido preparada, uma professora coloca o medo e a insegurança de não conseguir atender as exigências de sua profissão: "Porque no início você se sente com medo e que não vai dar conta do recado" (Professor 5). Já a professora que se sentiu muito preparada ao iniciar a docência, atribui o mérito a seus professores. Com relação às professoras que se sentiram preparadas "em termos" a justificativa se deve ao reconhecimento de estarem em constante processo de aperfeiçoamento profissional, pois há sempre novos desafios.

Em relação aos sentimentos que experimentam ou experimentaram no cotidiano da sala de aula, a maioria abordou diversos sentimentos contraditórios: "Irritação, pois há alunos com diversas personalidades difíceis, angústia, preocupação, raiva, decepção, culpa, alegria, amor. São sentimentos que envolvem nessa relação e procuram onde há o erro e melhorar, buscar soluções para o conflito" (Professora 1). Pode-se observar que resposta dada por essa professora vai ao encontro de Tardif e Raymond (2000, p.) ao afirmarem que "os cinco ou sete primeiros anos da carreira representam um período crítico de aprendizagem intensa da profissão, período esse que suscita expectativas e sentimentos fortes e, às vezes, contraditórios, nos novos professores".

Uma dificuldade que também se apresenta nas respostas dos professores, diz respeito à relação com os pais: "Em sala a maior dificuldade é lidar com as famílias que quase nunca colaboram para o desenvolvimento e aprendizado dos filhos" (Professor 3). Em razão dessa fala, Pinto (2009) comenta que estabelecer uma aliança entre profissionais da educação, pais e alunos da rede pública de ensino, talvez seja a tarefa mais urgente, no entanto, a mais difícil, para os diversos segmentos da população que lutam por uma escola pública de qualidade. 
Procurou-se também verificar nas respostas dadas pelas professoras se possuem uma boa relação interpessoal com os diversos segmentos da escola, ou seja: direção, coordenação, funcionários, pais, alunos e demais professores. Para tanto, foi solicitado que as participantes atribuíssem um valor entre 1 a 5 , sendo que 1 representava o pior relacionamento e 5 um ótimo relacionamento interpessoal. Nesse item, $100 \%$ das participantes consideraram ter uma ótima relação com os seus pares, ou seja, professores da escola em que atuam.

Por outro lado, constatou-se que as menores notas atribuídas foram aos pais dos alunos, pois, $40 \%$ dos professores atribuíram valores entre 1 e 2 , ou seja, a relação é muito ruim. É preocupante ainda que $20 \%$ dos professores também consideraram que mantêm uma relação muito ruim com os alunos. Trata-se de um dado bastante preocupante, uma vez que o aluno deve ser considerado o centro do processo educativo. Quanto ao relacionamento com a família convém lembrar que o documento Política Nacional de Educação Infantil (BRASIL, 2009) ressalta a necessidade de que a educação familiar e a escolar se complementem e se enriqueçam, propiciando assim, aprendizagens concretas, coerentes, mais amplas e profundas.

Quando indagadas se receberam apoio no início da carreira, $60 \%$ disseram que receberam todo o suporte e $40 \%$ disseram ter recebido apoio em termos, justificando que um ou mais companheiros de trabalho não as deixaram desistir. Em relação às professoras que não receberam todo o apoio que esperavam, Huberman (1995) ressalta que a profissão docente é uma, das poucas profissões, em que o professor é jogado e inserido no mercado de trabalho sem sequer ter um acompanhamento sistemático por parte da coordenação pedagógica e direção escolar. No entanto, constata-se que a todo momento os professores se deparam com desafios e que, apesar de todas as dificuldades, eles demonstram em suas falas que gostam e sabem da importância de ser professor e têm compromisso com a sua formação: "O que me faz continuar é saber que sou e estou sendo preparada para tal trabalho e não desisto na primeira dificuldade"(Professor 4).

\section{CONSIDERAÇÕES FINAIS}

Não se pode desconsiderar que professor iniciante possui necessidades formativas específicas que precisam ser ouvidas e, portanto, exigem uma atenção especial tanto das instituições formadoras, quanto das políticas públicas e dos gestores da escola básica.

Das instituições formadoras ao buscarem inserir os futuros docentes em projetos que tenham como foco os problemas vivenciados na escola básica; do poder público espera-se que sejam viabilizados todos os recursos legais e financeiros para uma política comprometida com da formação e valorização docente; dos gestores escolares ao assumirem uma atitude de acolhimento para com o professor iniciante, de forma a garantir espaços de compartilhamento com seus pares de suas dificuldades, inseguranças e propostas nas quais acreditam, bem como possibilitar que a escola seja um fórum de discussão permanente sobre a prática pedagógica.

Por fim, cabe lembrar que é essencial que o professor iniciante tenha uma ação pautada no aprender a aprender permanente, mobilizada pelo compromisso com o direito que toda criança tem a uma aprendizagem significativa e emancipatória.

\section{REFERÊNCIAS}

ALMEIDA, Claudia Mara de; SOARES, Kátia Cristina Dambiski. Professor de educação infantil e anos iniciais do ensino fundamental: aspectos históricos e legais da formação (livro eletrônico). Curitiba: Intersaberes, 2012. Disponível em: http://unoeste.bv3.digitalpages.com.br/users/publications/9788582121986/pages/1. Acesso em 15 maio 2016.

ARAÚJO, Regina Magna Bonifácio de. A formação dos professores para a educação infantil: novos olhares. Revista de Educação do Cogeime, ano 14, n. 27, p. 55 -65, dez. 2005. 
BRASIL. Ministério da Educação. Secretaria de Educação Básica. Política de educação infantil no Brasil: Relatório de avaliação. Ministério da Educação, Secretaria de Educação Básica. Brasília: MEC, SEB; Unesco, 2009.

Lei n. 13005, de 25 de junho de 2014. Aprova o Plano Nacional de Educação - PNE e dá outras providências. Diário Oficial da União. Poder legislativo, Brasília, DF, 26 jun. 2014. Disponível em: http://www.planalto.gov.br/CCIVIL 03/ Ato2011-2014/2014/Lei/L13005.htm. Acesso em 15 de maio de 2016.

CODO, Vanderlei. (org). Educação: Carinho e Trabalho - Burnout, a síndrome da desistência do educador, que pode levar à falência da educação. Petrópolis, RJ: Vozes/ Brasília: CNTE: UNB, Laboratório de Psicologia do Trabalho, 1999.

GABARDO, Cláudia Valéria e HOBOLD Márcia de Souza. Início da docência: investigando professores do ensino fundamental. Formação Docente, Belo Horizonte, v. 03, n. 05, p. 85-97, ago./dez. 2011. Disponível em http://formacaodocente.autenticaeditora.com.br Acesso em: 20 maio 2016.

HUBERMAN, M. O ciclo de vida profissional dos professores. In: NÓVOA, A. (Org.). Vidas de professores. 2 ed. Portugal: Porto Editora, 1995. cap. II. p. 31-61.

IMBERNÒN, Francisco. Formação Docente e Profissional: formar-se para a mudança e a incerteza. 9 ed. São Paulo: Cortez, 2011.

MARCELO, Carlos. Desenvolvimento profissional docente: passado e futuro. Revista de Ciências da Educação, n. 8, p. 7-22, jan/abr. 2009. Disponível em:

http://www.fep.porto.ucp.pt/sites/default/files/files/FEP/SAME/docs/Carlosmarcelo Desenv Pro fissional.pdf. Acesso em: 14 maio 2014.

NONO, Maévi A.; MIZUKAMI, Maria da Graça N. Processos de formação de professoras iniciantes. Revista Brasileira de Estudos Pedagógicos, v. 87, n. 217, p. 382-400, 2006. Disponível em: http://rbep.inep.gov.br/index.php/rbep/article/viewFile/812/787. Acesso em: 28 mar 2014. PERRENOUD, Philippe. A prática reflexiva no ofício de professor: profissionalização e razão pedagógica. Porto Alegre: Artmed, 2002.

PIMENTA, Selma Garrido. Professor reflexivo: Construindo uma crítica. PIMENTA, Selma Garrido, GHEDIN, Evandro (Orgs.). Professor reflexivo no Brasil: gênese e crítica de um conceito. 3. ed. São Paulo: Cortez, 2005, p. 17-52.

PINTO José Marcelino Rezende. Remuneração adequada do professor Desafio à educação brasileira. Revista Retratos da Escola, Brasília, v. 3, n. 4, p. 51-67, jan./jun. 2009. Disponível em: http//www.esforce.org.br. Acesso em: 15 maio 2016

SILVEIRA, Marco Aurelio; RAUSCH, Rita Buzzi. Desafios de Professores iniciantes da Educação Infantil e dos anos iniciais da Educação Fundamental. In: Congresso Internacional sobre Professor Iniciante e Inserção Profissional 'Docência, IV, 2014 Curitiba, Anais. Curitiba: Universidade Tecnológica Federal do Paraná, 2014, p. 101-112. Disponível em: http://congressoprinc.com.br/artigo?id artigo=68 . Acesso em: 16 mar 2016 
TANURI, Leonor Maria. História da formação de professores. Revista Brasileira de Educação, n. 14, p. 61-68, mai/jun/jul/ago. 2002. Disponível em: http://www.scielo.br/pdf/rbedu/n14/n14a05.

Acesso em: 12 ago 2014.

TARDIF, Maurice; RAYMOND, Danielle. Saberes, tempo e aprendizagem do trabalho no magistério. Educação \& Sociedade, ano XXI, no 73, p. 209-244, Dez 2000. Disponível em: http://www.scielo.br/pdf/es/v21n73/4214.pdf . Acesso em: 15 maio 2014

TARDIFF, Maurice. Saberes Docentes e Formação Profissional. 16 ed. Rio de Janeiro: Vozes, 2014. 